\title{
TRPM8 Mechanism of Cold Allodynia after Chronic Nerve Injury
}

\author{
Hong Xing, ${ }^{1 *}$ Meng Chen, ${ }^{1 *}$ Jennifer Ling, ${ }^{1}$ Weihong Tan, ${ }^{2}$ and Jianguo G. Gu${ }^{1}$ \\ ${ }^{1}$ Department of Oral and Maxillofacial Surgery, McKnight Brain Institute and College of Dentistry, University of Florida, Gainesville, Florida 32610, and \\ ${ }^{2}$ Department of Chemistry, Shands Cancer Center, University of Florida Genetics Institute, and McKnight Brain Institute, University of Florida, Gainesville, \\ Florida 32611-7200
}

The cold- and menthol-sensitive receptor TRPM8 (transient receptor potential melastatin 8) has been suggested to play a role in cold allodynia, an intractable pain seen clinically. We studied how TRPM8 is involved in cold allodynia using rats with chronic constrictive nerve injury (CCI), a neuropathic pain model manifesting cold allodynia in hindlimbs. We found that cold allodynic response in the CCI animals was significantly attenuated by capsazepine, a blocker for both TRPM8 and TRPV1 (transient receptor potential vanilloid 1) receptors, but not by the selective TRPV1 antagonist I-RTX (5-iodoresiniferatoxin). In L5 dorsal root ganglion (DRG) sections of the CCI rats, immunostaining showed an increase in the percentage of TRPM8-immunoreactive neurons when compared with the sham group. Using the $\mathrm{Ca}^{2+}$-imaging technique and neurons acutely dissociated from the L5 DRGs, we found that CCI resulted in a significant increase in the percentage of menthol- and cold-sensitive neurons and also a substantial enhancement in the responsiveness of these neurons to both menthol and innocuous cold. These changes occurred in capsaicin-sensitive neurons, a subpopulation of nociceptive-like neurons. Using patch-clamp recordings, we found that membrane currents evoked by both menthol and innocuous cold were significantly enhanced in the CCI group compared with the sham group. By retrograde labeling afferent neurons that target hindlimb skin, we showed that the skin neurons expressed TRPM8 receptors, that the percentage of menthol-sensitive/cold-sensitive/capsaicin-sensitive neurons increased, and that the menthol- and cold-evoked responses were significantly enhanced in capsaicin-sensitive neurons after CCI. Together, the gain of TRPM8-mediated cold sensitivity on nociceptive afferent neurons provides a mechanism of cold allodynia.

Key words: TRPM8; cold allodynia; pain; chronic nerve injury; calcium imaging; patch-clamp recording

\section{Introduction}

The cloning of transient receptor potential melastatin 8 (TRPM8) has generated great interest in its role in cold allodynia (McKemy et al., 2002; Peier et al., 2002) and its use as a therapeutic target (Levine and Alessandri-Haber, 2007). Cold allodynia is pathological pain induced by innocuous cold. The pain is intractable and often occurs in patients with complex regional pain syndrome; approximately $80 \%$ of these patients suffer from cold allodynia (Kemler et al., 2000). Cold allodynia is also present in other disease conditions such as fibromyalgia and diabetic neuropathy (Tahmoush et al., 2000; Vinik, 2004).

TRPM8 is an ion channel that belongs to the transient receptor potential family (Tominaga and Caterina, 2004). When expressed in heterologous cells, temperatures below $26 \pm 2{ }^{\circ} \mathrm{C}$ start to evoke membrane currents flowing through TRPM8 (McKemy et al., 2002; Peier et al., 2002). TRPM8 currents increase with

\footnotetext{
Received May 14, 2007; revised Sept. 17, 2007; accepted Sept. 17, 2007.

We thank Drs. Charles Vierck, Richard Johnson, and Robert Caudle for technical assistance in producing the CCI animal model and behavioral assessment; Dr. Makoto Tominaga for the TRPM8 antibody; and Dr. Brian Cooper for the thoughtful comments in this manuscript preparation.

H.X. and M.C. contributed equally to this work.

Correspondence should be addressed to Dr. Jianguo G. Gu, Department of Oral and Maxillofacial Surgery, McKnight Brain Institute and College of Dentistry, University of Florida, Box 100416, Gainesville, FL 32610. E-mail: jgu@dental.ufl.edu.

DOI:10.1523/JNEUROSCI.2203-07.2007

Copyright $\odot 2006$ Society for Neuroscience $\quad$ 0270-6474/06/2613680-11\$15.00/0
}

decreases in temperatures and reach maximum currents near $10^{\circ} \mathrm{C}$. Thus, TRPM8 can sense temperature changes in the range of both innocuous cold $\left(15-28^{\circ} \mathrm{C}\right)$ and noxious cold $\left(<15^{\circ} \mathrm{C}\right)$. TRPM8 can also be activated by menthol, an ingredient of peppermint that produces a cooling sensation (McKemy et al., 2002; Peier et al., 2002; Reid and Flonta, 2002). TRPM8-expressing neurons are $\sim 10-15 \%$ of the total trigeminal ganglion neuron population and $5-10 \%$ of the dorsal root ganglion (DRG) neuron population (McKemy et al., 2002; Peier et al., 2002; Abe et al., 2005). The expression of TRPM8 on cold-sensing skin neurons has not been reported, but the requirement of TRPM8 in skin cold sensation has been demonstrated using TRMP8 null mice (Bautista et al., 2007; Colburn et al., 2007; Dhaka et al., 2007). In normal animals, a previous study showed that TRPM8expressing neurons did not appear to express any classical nociceptive neuron markers such as transient receptor potential vanilloid 1 (TRPV1) immunoreactivity (IR) (Peier et al., 2002). Recently, we found that a subpopulation of neurons with nociceptive properties (e.g., capsaicin sensitivity) also expresses functional TRPM8 receptors, but their expression level is low (Xing et al., 2006). Consistently, two other recent studies showed detectable TRPM8-IR in some TRPV1-expressing neurons of rats (Okazawa et al., 2004; Abe et al., 2005).

Peripheral mechanisms of cold allodynia are poorly understood. Recent studies using TRPM8 knock-out mice have sug- 
gested the involvement of TRPM8 in cold avoidance behavior and cold allodynia in mice (Bautista et al., 2007; Colburn et al., 2007; Dhaka et al., 2007), but it remains unknown how TRPM8 is associated with nociceptive input induced by innocuous cold. One hypothesis is that under pathological conditions, TRPM8 expression and/or function on nociceptive neurons are enhanced, resulting in the excitation of these neurons by innocuous cold and cold allodynia (Chung and Caterina, 2007). Consistent with this hypothesis, an immunochemical study suggested that nerve injury could upregulate TRPM8 expression (Proudfoot et al., 2006). Here, we tested the hypothesis by using chronic constrictive nerve injury (CCI) rats, a pain model that well represents clinical symptoms including cold allodynia in patients with peripheral neuropathy (Bennett and Xie, 1988; Kemler et al., 2000; Tahmoush et al., 2000).

\section{Materials and Methods}

CCI model and behavioral assessment. Adult Sprague Dawley rats (150$250 \mathrm{~g}$, both genders) were used in all experiments. Animal care and use conformed to National Institutes of Health guidelines for care and use of experimental animals. Experimental protocols were approved by the University of Florida Institutional Animal Care and Use Committee. The CCI model of Bennett and Xie (1988) was used with a slight modification (Vierck et al., 2005). In brief, animals were anesthetized with continuous inhalation of isofluorane. After an incision of mid-thigh and a separation of the heads of the biceps femoris muscle, the sciatic nerve was exposed. Proximal to the trifurcation into peroneal, tibial, and sural branches, $\sim 7$ $\mathrm{mm}$ of sciatic nerve was separated from adjacent connective tissue, and a $5 \mathrm{~mm}$ piece of 4-0 chromic gut was placed longitudinally under the epineurium within a tunnel created with a fine-tipped glass probe. Four loose ligatures of 4-0 chromic gut were then placed circumferentially around the outside of the nerve. The desired degree of constriction was a decrease in diameter of the nerve just barely detectable under a $40 \times$ microscope objective. To prevent the ligatures from loosening during recovery, each single-throw knot was stabilized with several tight ligatures of 7-0 monofilament. Sham surgical controls received the sciatic nerve exposures and isolation from surrounding tissue without epineurial tunneling or loose ligature placement. The wounds were closed in layers with 6-0 monofilament and $7 \mathrm{~mm}$ wound clips.

Animal behavioral responses to innocuous cold stimulation were tested by the acetone test (Choi et al., 1994). In brief, the rats were placed in a transparent plastic cage with small holes on the bottom and habituated to the test chamber for at least $30 \mathrm{~min}$ before the measurements. Acetone $(100 \mu \mathrm{l})$ was gently sprayed onto the plantar surface of the hindpaw using an Eppendorf (New York, NY) multistepper pipette connected with a blunt rubber tube. The brisk foot withdrawal response after the acetone spray was considered as a positive response, and the responses were graded to a four-point scale: 0 , no response; 1 , brisk withdrawal or flick of the paw; 2, repeated flicking of the paw; 3, repeated flicking of the hindpaw and licking of the paw (Choi et al., 1994; Flatters and Bennett, 2004). The acetone spray was applied five times with an interval of $5 \mathrm{~min}$ between each application. The frequency of foot withdrawal was expressed as a percentage: (number of trials accompanied by brisk foot withdrawal) $\times 100 /$ (number of total trials). The response scores were the average of the graded points in the five acetone spray trials.

Retrograde labeling of primary afferent neurons innervating the hindpaw skin. Seven days after the sham operation (18 rats) or CCI nerve ligation (17 rats), retrograde labeling was performed using the dicarbocyanine dye DiI (Invitrogen, Eugene, OR). In brief, animals were anesthetized with isofluorane and received injections of DiI into the glabrous footpads. The dye was prepared by dissolving $25 \mathrm{mg}$ of DiI in $0.5 \mathrm{ml}$ of ethanol. It was injected at 10 locations, $2 \mu \mathrm{l}$ each site, in the left or right glabrous plantar pads. The injection was made by using a 30 gauge needle attached to a Hamilton (Reno, NV) microsyringe. The needle was slowly withdrawn, and the small hole in the skin was sealed with a small drop of cyanoacrylate to prevent the dye from coming to the surface. The rats were used 1 week after the DiI injections.

Whole-DRG immunohistochemistry. Animals and tissue processing were performed as described in our previous studies (Petruska et al., 2000a, 2002). In brief, four rats from the CCI group and three rats from the sham group were overdosed with isofluorane, transcardially exsanguinated with heparinized saline, and perfused with $4 \%$ paraformaldehyde in PBS. Lumbar DRGs at the level of L5 of the ipsilateral side were removed immediately and placed in 30\% sucrose in PBS for cryoprotection overnight. Once the DRGs had equilibrated, they were embedded in OCT compound (Baxter Scientific, Deerfield, IL), and $10 \mu \mathrm{m}$ sections were cut on a cryostat. Sections were thaw mounted onto slides and allowed to air dry. They were then encircled with hydrophobic resin (PAP Pen; The Binding Site, San Diego, CA). The sections were incubated at room temperature for $2 \mathrm{~h}$ in a solution of $2 \%$ Triton $\mathrm{X}-100$ in PBS. They were rinsed three times with PBS and incubated in a solution of $1: 30$ normal goat serum in PBS with $0.4 \%$ Triton X-100 (GS-PBS-T) for $1 \mathrm{~h}$ to block nonspecific antibody binding. They were then washed three times with PBS solution. The sections were incubated overnight at $4^{\circ} \mathrm{C}$ with a polyclonal rabbit anti-TRPM8 receptor antibody (from Dr. M. Tominaga, Okazaki Institute for Integrative Bioscience, National Institute of Natural Sciences, Aichi, Japan) diluted 1:500 in 1\% GS-PBS-T. After rinse with $1 \%$ goat serum PBS solution three times, the slices were further incubated with a secondary antibody for $3 \mathrm{~h}$ at room temperature. The secondary antibody (1:100 in goat serum PBS solution) was a goat anti-rabbit IgG conjugated with Alexa-594 (Invitrogen). Slices were washed three times with $1 \%$ goat serum PBS solution, and the coverslip was applied with a glycerol-based anti-photobleach medium. Slices were viewed under an inverted fluorescent microscope (IX-70; Olympus, Tokyo, Japan). For each L5 DRG ganglion, three sections that were $140 \mu \mathrm{m}$ apart were selected for quantification of IR and cell counts. Two to three optical fields $(500 \times 500 \mu \mathrm{m})$, from three sections of each DRG, were randomly captured and digitized. Only the neurons that had clearly visible nuclei and nucleoli were counted. The optical intensity of IR was quantified using a 255-level grayscale by the Scion Imaging Program (Scion, Frederick, MD). To determine immunoreactive positive neurons in each DRG section, a threshold was set at 2.5 times of averaged cytoplasmic intensity level. All neurons sectioned through their nuclei for which mean optical intensity exceeded the threshold were counted as positive, and the number of positive cells was expressed as a percentage of total counted DRG neurons. To visualize all neuronal profiles, sections were incubated with ethidium bromide $(5 \mu \mathrm{g} / \mathrm{ml})$ for $30 \mathrm{~s}$ after secondary antisera incubation and were then washed with PBS.

Preparation of acutely dissociated DRG neurons. Acutely dissociated DRG neurons were prepared as described in our previous work (Petruska et al., 2000a,b). In brief, ipsilateral L5 DRGs were dissected out from the CCI group or the sham group. They were incubated with dispase II (5 $\mathrm{mg} / \mathrm{ml})$ and type I collagenase $(2 \mathrm{mg} / \mathrm{ml})$ in $2 \mathrm{ml}$ of bath solution at $37^{\circ} \mathrm{C}$ for $45 \mathrm{~min}$. The bath solution was the same one used for cell perfusion in $\mathrm{Ca}^{2+}$ imaging and electrophysiology experiments (see below). After a rinse, DRGs were triturated to dissociate the neurons in the bath solution, and the dissociated cells were plated on glass coverslips coated with poly-D-lysine and maintained in the oxygenated bath solution at room temperature. Calcium imaging and whole-cell patch recording experiments were performed within 1-4 h.

Calcium imaging and patch-clamp recordings. Calcium imaging experiments were performed using a method described in our previous work (Xing et al., 2006). In brief, the DRG neurons on coverslips were incubated with $5 \mu \mathrm{M}$ Fluo-3-AM in 20\% pluronic acid (Invitrogen) for $30 \mathrm{~min}$ at $37^{\circ} \mathrm{C}$. After the dye loading, the cells were perfused with normal bath solution in a $0.5 \mathrm{ml}$ chamber on the stage of an Olympus IX-70 microscope. Cells were continuously perfused with bath solution flowing at 1 $\mathrm{ml} / \mathrm{min}$. The bath solution contained the following (in mM): $150 \mathrm{NaCl}, 5$ $\mathrm{KCl}, 2 \mathrm{MgCl}_{2}, 2 \mathrm{CaCl}_{2}, 10$ glucose, and 10 HEPES, pH 7.4, osmolarity of $320 \mathrm{mOsm}$. Unless indicated otherwise, the basal temperature of the bath solution in the recording chamber was maintained at $30 \pm 1^{\circ} \mathrm{C}$ with a customer-made thermal-control system. Fluo-3 fluorescence was detected with a peltier-cooled charge-coupled device camera (PentaMAXIII System; Roper Scientific, Trenton, NJ) under a $10 \times$ objective. Exci- 
tation was at $450 \mathrm{~nm}$, and emission was at 550 $\mathrm{nm}$, achieved by a fluorescence filter set. Images were taken at one frame per second and digitized using the software MetaFluor (Universal Imaging Corporation, West Chester, PA). In some experiments, cold- and mentholsensitive neurons identified with calcium imaging were patch clamp recorded under wholecell voltage-clamp configuration with the cells held at $-70 \mathrm{mV}$. The internal solution of electrodes contained the following (in $\mathrm{mM}$ ): 135 K-gluconate, $0.5 \mathrm{CaCl}_{2}, 2 \mathrm{MgCl}_{2}, 5 \mathrm{KCl}, 5$ EGTA, 10 HEPES, $2 \mathrm{Na}_{2}$-ATP, and $0.5 \mathrm{Na}_{2}-$ GTP, pH 7.2, osmolarity of 315-325 mOsm. Recording electrode resistance was between 3.0 and 5.0 M $\Omega$. The junction potential was -9 $\mathrm{mV}$ and was not adjusted. The series resistance of each recording was below $30 \mathrm{M} \Omega$ and was not compensated. In each experiment before the application of a stimulant, baseline current for each cell was smaller than $-100 \mathrm{pA}$. Cells were not used when baseline currents were larger (more negative) than $-100 \mathrm{pA}$. Recording signals were amplified with Axopatch 200B (Molecular Devices, Union City, CA), filtered at $2 \mathrm{kHz}$, and sampled at $5 \mathrm{kHz}$ using pCLAMP 8 (Molecular Devices). For both calcium imaging and patch-clamp recording experiments, cold stimulation was achieved by application of a cold bath solution, which yielded a temperature drop in the recording site from $30^{\circ} \mathrm{C}$ to $\sim 18^{\circ} \mathrm{C}$ in $20 \mathrm{~s}$. Testing compounds, including menthol, capsaicin, capsazepine, and 5-iodoresiniferatoxin (I-RTX), were rapidly applied to neurons through a glass tube (inner diameter, $500 \mu \mathrm{m}$ ) positioned $0.5 \mathrm{~mm}$ away from cells. For calcium imaging experiments, menthol or capsaicin was applied for $20 \mathrm{~s}$; for electrophysiology experiments, menthol or capsaicin was applied for $10 \mathrm{~s}$. Capsazepine or I-RTX was preapplied for $20 \mathrm{~s}$ and coapplied with the stimulants tested. Unless indicated otherwise, intervals between drug applications were $10 \mathrm{~min}$. All these testing compounds were purchased from Sigma (St. Louis, MO).

Data analysis. For calcium imaging experiments, relative fluorescence intensity $\left(\Delta F / F_{0}\right)$ was used with values of $>0.2$ (i.e., $20 \%$ increases) considered as responsive cells (Xing et al., 2006). Electrophysiology data recorded from DRG neurons were analyzed using Clampfit 8.2 (Molecular Devices). The amplitudes of currents were measured at their peaks. Current amplitude was normalized by membrane surface areas (i.e., TRPM8 current density). For cell membrane surface areas, each cell is considered to be a sphere, and its area is calculated based on the averaged diameter. Parametric data are presented as mean \pm SEM, and Student's $t$ tests or ANOVA tests were used for statistical comparison among groups. The $\chi^{2}$ test was used for statistical analysis of nonparametric data. Statistical significance was considered at the level of the $p<0.05$.

\section{Results}

Forty-one rats that received the chronic constrictive nerve ligation showed cold allodynic responses to the acetone test a few days after CCI. These responses included quick withdrawal of the paw, flick or stamp of the paw, prolonged withdrawal or repeated flicking of the paw, and repeated flicking of the paw with licking directed at the mean \pm SEM. ${ }^{*} p<0.05$.
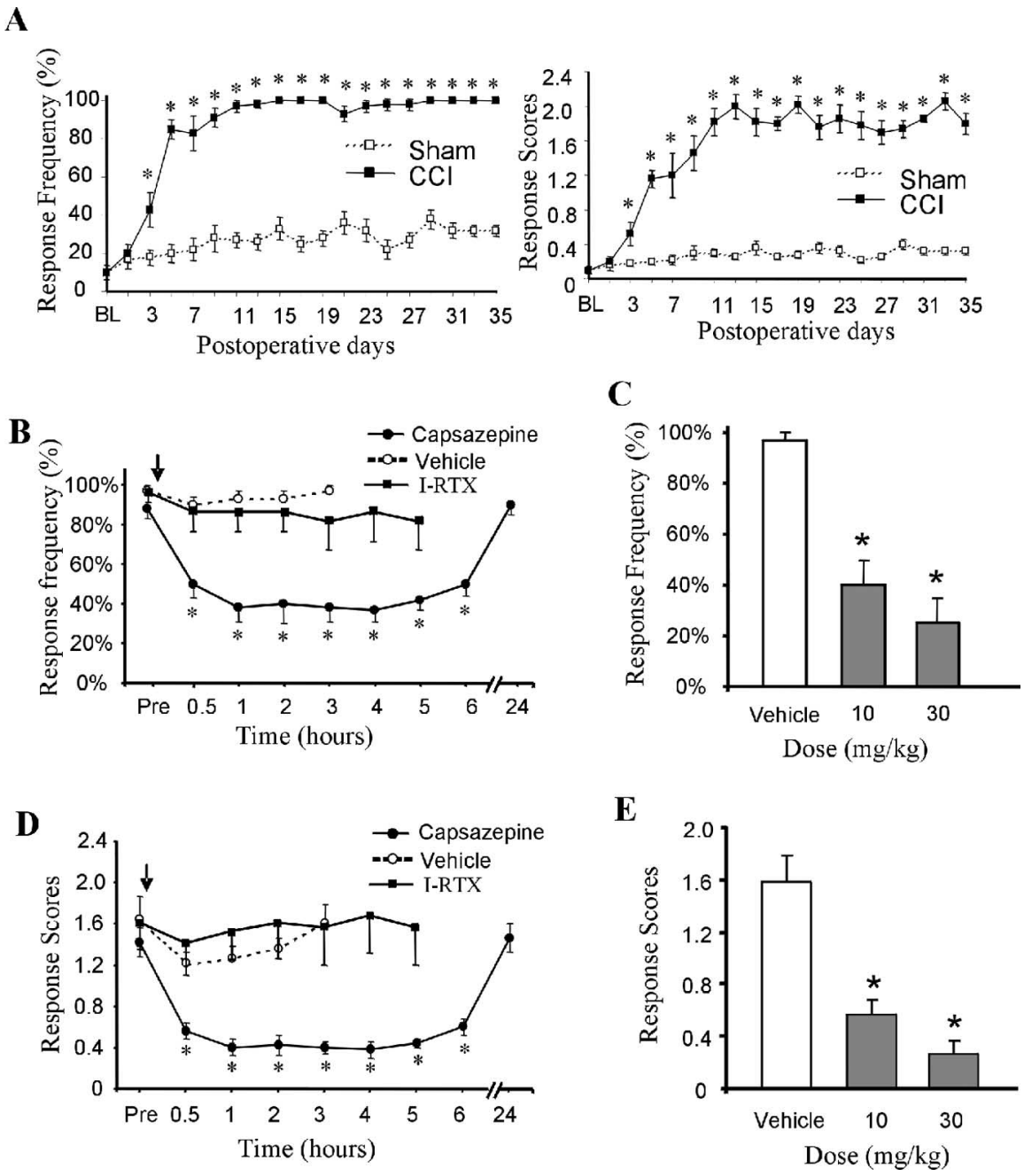

Figure 1. Attenuation of cold allodynic responses by capsazepine in the $\mathrm{CCl}$ model. $\boldsymbol{A}$, Time course of cold allodynic responses to the acetone test in ipsilateral hindpaws of the $(C \mathrm{C}$ rats (filled squares; $n=10$ ) and the sham rats (open squares; $n=8$ ). The response frequency in the $\mathrm{CCl}$ rats before and after an intraperitoneal single-dose injection of $10 \mathrm{mg} / \mathrm{kg}$ capsazepine (filled circles; $n=12$ ), $0.75 \mathrm{mg} / \mathrm{kg} \mathrm{I-RTX} \mathrm{(filled} \mathrm{squares;} n=4$ ), and vehicle (open circles; $n=6$ ). The arrow indicates the injections of the testing compounds or vehicle. C, Summary of cold allodynic response frequency after the administration of vehicle (open bar; $n=$ 6), $10 \mathrm{mg} / \mathrm{kg}$ capsazepine (first filled bar; $n=12$ ), and $30 \mathrm{mg} / \mathrm{kg}$ capsazepine (second filled bar; $n=6$ ). $\boldsymbol{D}$, Time course of cold circles; $n=12$ ), $0.75 \mathrm{mg} / \mathrm{kg} \mathrm{I-RTX} \mathrm{(filled} \mathrm{squares;} n=4$ ), and vehicle (open circles; $n=6$ ). The arrow indicates the injections of the testing compounds or vehicle. $\boldsymbol{E}$, Summary of cold allodynic response scores after the administration of vehicle (open bar; $n=$ point after the injections of capsazepine or vehicle were used for the construction of the bar graph in $\boldsymbol{C}$ and $\boldsymbol{E}$. Error bars indicate

ventral side of the paw. Ten of these animals were tested continuously for 5 weeks for the time course of cold allodynic responses. As shown in Figure 1, the responses to multiple acetone tests, expressed as response frequency (Fig. $1 A$, left) or response scores (Fig. $1 A$, right), reached maximum levels in $\sim 1$ week after the nerve ligation. The responses thereafter were maintained at the same level for at least 5 weeks $(n=10)$ (Fig. $1 A)$. The remaining $31 \mathrm{CCI}$ animals showed similar responses at the time $(\sim 2$ weeks $)$ when they were used for different experiments described below. In contrast to the CCI group, 8 rats that received sham operation did not show any significant increase in the behavioral responses to the acetone test in 5 weeks $(n=8)$ (Fig. $1 A)$, and 32 other sham rats also did not have cold allodynic responses at the time $(\sim 2$ weeks) when they were used for other experiments described below. 
A

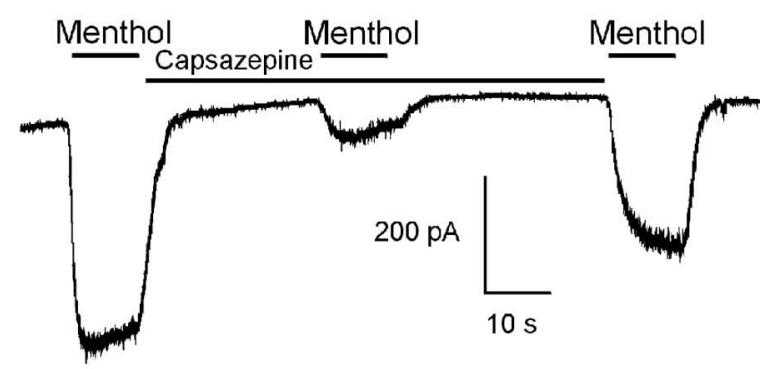

B

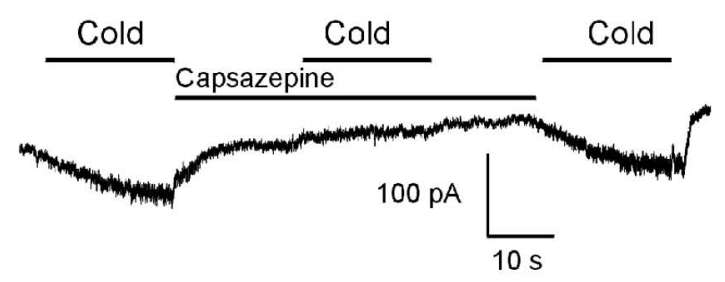

C
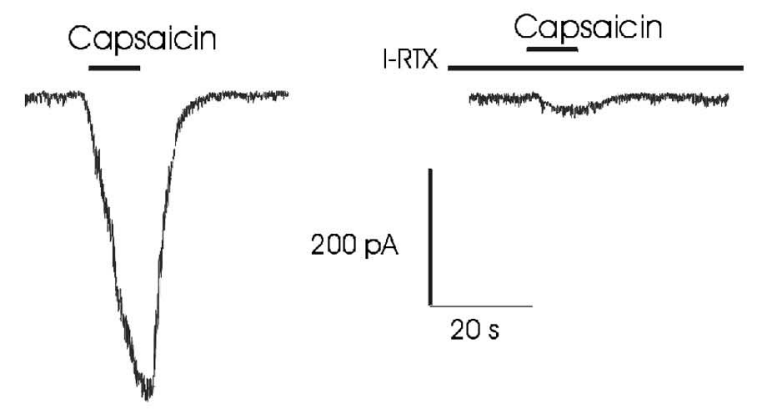

D

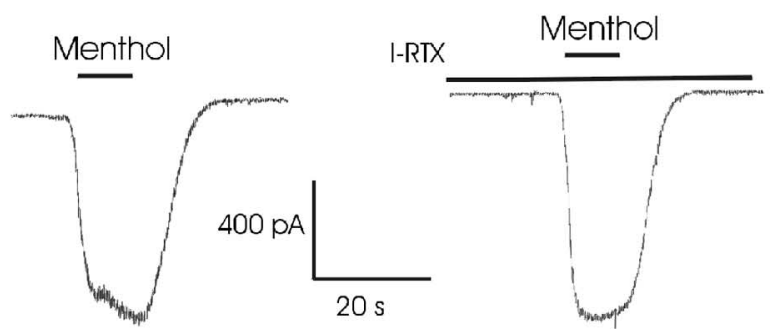

Figure 2. Inhibition by capsazepine on menthol- and cold-induced currents in sensory neurons. $\boldsymbol{A}$, Whole-cell currents evoked by $100 \mu \mathrm{m}$ menthol in the absence and presence of $100 \mu \mathrm{m}$ capsazepine. Similar results were obtained in eight other DRG neurons. $\boldsymbol{B}$, The recording was made from the same cell shown in $\boldsymbol{A}$. Cold stimulation (temperature drop from $24^{\circ} \mathrm{C}$ to $18^{\circ} \mathrm{C}$ ) was tested in the absence and presence of $100 \mu \mathrm{m}$ capsazepine. Similar results were obtained from two other cells. $\boldsymbol{C}$, Whole-cell currents on a DRG neuron evoked by $0.5 \mu \mathrm{m}$ capsaicin in the absence (left) and presence (right) of $0.1 \mu \mathrm{m} \mathrm{I-RTX.} \mathrm{Similar} \mathrm{results} \mathrm{were} \mathrm{obtained} \mathrm{in} \mathrm{three} \mathrm{other}$ acutely dissociated DRG neurons. $D$, Whole-cell currents on a DRG neuron evoked by $100 \mu \mathrm{m}$ menthol in the absence (left) and presence (right) of $0.1 \mu \mathrm{m} \mathrm{I-RTX.} \mathrm{Similar} \mathrm{results} \mathrm{were} \mathrm{obtained}$ in three other acutely dissociated DRG neurons.

We tested capsazepine, a blocker for both TRPV1 and TRPM8 receptors, to see whether it could attenuate cold allodynic responses in the CCI animals. In this set of experiments, the CCI rats on postoperative day 14 were used; all the animals showed high response frequency $(90 \pm 3 \% ; n=12)$ (Fig. $1 B)$ and high response scores $(1.43 \pm 0.17 ; n=12)$ (Fig. $1 D)$ to the acetone test before capsazepine treatment. After a single intraperitoneal injection of capsazepine at the dose of $10 \mathrm{mg} / \mathrm{kg}$, there was a significant reduction in response frequency (Fig. $1 B$ ) and response scores (Fig. $1 D$ ) to the acetone test. The inhibitory effect with the single dose of capsazepine lasted for $\sim 6 \mathrm{~h}$, and the cold allodynic responses returned to the level before capsazepine treatment (Fig. $1 B, D)$. The response frequency to the acetone test was $40 \pm 10 \%$ (Fig. $1 B, C)(n=12 ; p<0.05)$ with a capsazepine dose of 10 $\mathrm{mg} / \mathrm{kg}$ and $25 \pm 10 \%$ (Fig. $1 C)(n=4 ; p<0.05)$ with a capsazepine dose of $30 \mathrm{mg} / \mathrm{kg}$; both significantly lower than the responses to the acetone test when vehicle was injected (95 $\pm 3 \%$; $n=6$ ) (Fig. $1 B, C$ ). The response scores to the acetone test were $0.56 \pm 0.12$ (Fig. $1 D, E)(n=12 ; p<0.05)$ with a capsazepine dose of $10 \mathrm{mg} / \mathrm{kg}$ and $0.26 \pm 0.1$ (Fig. $1 E)(n=4 ; p<0.05)$ with a capsazepine dose of $30 \mathrm{mg} / \mathrm{kg}$, both significantly lower than the responses to the acetone test when vehicle was injected $(1.61 \pm$ $0.21 ; n=6$ ) (Fig. $1 D, E$ ). Vehicle injection did not significantly change the cold allodynic response frequency (Fig. $1 B, C$ ) and response scores (Fig. $1 D, E)$ in the CCI animals $(n=6)$.

To examine whether or not the inhibition of TRPV1 receptors accounted for the suppression of cold allodynic responses by capsazepine, we tested I-RTX, a TRPV1 antagonist that is $\sim 1000$ times more potent than capsazepine (Seabrook et al., 2002; Correll et al., 2004; Kanai et al., 2006), to see whether it might produce an inhibitory effect similar to capsazepine. We did not find any significant difference in the acetone test on the CCI rats before and after I-RTX treatment $(0.75 \mathrm{mg} / \mathrm{kg} ; n=4)($ Fig. $1 B, D)$.

Using patch-clamp recordings from acutely dissociated DRG neurons, we found that capsazepine strongly inhibited mentholand cold-evoked inward currents. Of nine menthol-sensitive neurons tested, menthol-evoked currents in the presence of 100 $\mu \mathrm{M}$ capsazepine were only $\sim 20 \%(20 \pm 2.8 \% ; n=9 ; p<0.05)$ (Fig. 2A) of the menthol-evoked currents in the absence of capsazepine. Three menthol-sensitive neurons were tested with cold stimulation (temperature ramp from 24 to $18^{\circ} \mathrm{C}$ ) in the absence and presence of $100 \mu \mathrm{M}$ capsazepine. Although all the three cells showed inward currents in responses to the cold stimulation in the absence of capsazepine, no detectable inward currents were evoked by the cold stimulation in the presence of $100 \mu \mathrm{M}$ capsazepine (Fig. $2 B$ ). We tested effects of I-RTX on currents evoked by capsaicin and menthol in DRG neurons. I-RTX $(0.1 \mu \mathrm{M})$ almost completely blocked the inward currents evoked by the TRPV1 agonist capsaicin $(0.5 \mu \mathrm{M} ; n=4)$ (Fig. $2 C)$, but it had no effect on the inward currents evoked by the TRPM8 agonist menthol (100 $\mu \mathrm{M} ; n=4)($ Fig. $2 D)$. These results are consistent with a previous study on I-RTX and indicate that I-RTX is highly selective to TRPV1 receptors (Behrendt et al., 2004). The results of capsazepine and I-RTX together suggested that the inhibition of TRPM8 receptors, rather than the inhibition of TRPV1, might account for the behavioral attenuation of cold allodynic responses by capsazepine.

To provide cellular evidence supporting the idea that cold allodynia is associated with a change in TRPM8 receptor expression after nerve injury, we examined TRPM8-IR in L5 DRGs using a previously characterized TRPM8 antibody (Obata et al., 2005). TRPM8-immunoreactive positive neurons were $\sim 7 \%$ $(7.2 \pm 0.7 \% ; 60$ of 829 cells; $n=20$ fields $)$ in the L5 DRG sections obtained from three control animals (Fig. $3 A, C$ ). In contrast, TRPM8-immunoreactive positive neurons in the L5 DRG sections obtained from four CCI rats were 15\% (15.0 $\pm 0.8 \%$; 218 of 1455 cells; $n=28$ fields) (Fig. $3 B, C$ ), more than twice that of TRPM8-immunoreactive positive neurons in L5 DRG sections of control rats $(p<0.05)$. These results suggest an increase in TRPM8 receptor expression in L5 DRGs of the CCI animals.

We used calcium imaging to examine whether there was an increase in the responsiveness of L5 DRG neurons to the TRPM8 agonist menthol and cold after chronic nerve injury. In this set of 
experiments, 10 CCI rats and 11 sham rats were used, and L5 DRGs were obtained from the ipsilateral side of these animals. DRG neurons were then acutely dissociated (without culture) and tested for their sensitivity to menthol $(100 \mu \mathrm{M})$ and cold (from $30^{\circ} \mathrm{C}$ to $18^{\circ} \mathrm{C}$ ). All these neurons were also tested with capsaicin $(0.5 \mu \mathrm{M})$ to see whether the change in menthol and cold responsiveness might occur in nociceptive-like (capsaicinsensitive) neurons. As shown in Figure $4 A$ in the sham group, there were two types of menthol-sensitive neurons: mentholsensitive/capsaicin-sensitive (MS/CS) neurons and mentholsensitive/capsaicin-insensitive (MS/CIS) neurons. Similarly, both MS/CS and MS/CIS neurons were observed in the CCI group (Fig. $4 B$ ). Both MS/CS and MS/CIS neurons responded to cold stimulation (Fig. $4 A, B$ ). When the responsiveness to menthol was compared between the CCI group and sham group, we found that MS/CS neurons had significantly higher responsiveness in the CCI group than in the sham group (Fig. 4C). The averaged peak response to menthol $(100 \mu \mathrm{M})$ in MS/CS neurons, expressed as the increase in fluo-3 fluorescence intensity $\left(\Delta F / F_{0}\right)$, was $1.12 \pm 0.09(n=46 ; p<0.05)$ in the CCI group and $0.67 \pm$ $0.13(n=18)$ in the sham group (Fig. $4 C)$. When MS/CS neurons were tested with cold stimulation by a temperature drop in a bath solution from $30^{\circ} \mathrm{C}$ to $18^{\circ} \mathrm{C}$, all of the MS/CS neurons responded to the cold stimulation with the increases of fluo-3 fluorescence intensity. Similar to menthol responses, we found that MS/CS neurons had significantly higher responsiveness to cold stimulation in the CCI group than in the sham group (Fig. $4 D$ ). The averaged peak response $\left(\Delta F / F_{0}\right)$ to the cold stimulation was $0.84 \pm 0.07(n=46 ; p<0.05)$ in the CCI group and $0.57 \pm 0.12$ $(n=18)$ in the sham group. For MS/CIS neurons, their responsiveness to menthol and cold appeared to be also higher in the CCI group than in the sham group, but the differences did not reach statistical significance. The averaged peak responses $(\Delta F /$ $\left.F_{0}\right)$ of MS/CS neurons to $100 \mu \mathrm{M}$ menthol were $1.34 \pm 0.22(n=$ $24)$ in the CCI group and $1.18 \pm 0.13(n=22)$ in the sham group (Fig. $4 E$ ). All these MS/CIS neurons were also sensitive to cold (from $30^{\circ} \mathrm{C}$ to $18^{\circ} \mathrm{C}$ ), and the averaged peak responses $\left(\Delta F / F_{0}\right)$ were $1.16 \pm 0.21(n=24)$ in the CCI group and $0.88 \pm 0.13(n=$ 22 ) in the sham group (Fig. $4 F$ ).

We next examined whether there was an increase in the number of menthol- and cold-sensitive neurons in the L5 DRGs of the CCI animals compared with the L5 DRG neurons of the sham group. In the sham group, $\sim 6 \%(6.2 \pm 0.6 \%$; 74 of 1186 cells; $n=$ 12) cells were menthol- and cold-sensitive neurons. In contrast, in the CCI group, $\sim 10 \%(10.4 \pm 0.9 \% ; 121$ of 1163 cells; $n=12)$ cells were menthol- and cold-sensitive neurons. The percentage of MS/CS neurons in the CCI group was significantly higher than that of the sham group $(p<0.05)$ (Fig. 5). When these mentholsensitive (also cold-sensitive) neurons were classified by their sensitivity to capsaicin $(0.5 \mu \mathrm{M}), 7 \%$ ( $7.1 \pm 0.8 \%$; 82 of 1163 cells; $n=12$ ) of them were MS/CS in the CCI group, but only $3 \%$ $(3.0 \pm 0.5 \%$; 36 of 1186 cells; $n=12)$ of the menthol-sensitive cells were MS/CS in the sham group (Fig. 5). MS/CIS neurons accounted for $3.4 \%(3.4 \pm 0.7 \%$; 40 of $1163 ; n=12)$ in the CCI group and $3.2 \%(3.2 \pm 0.5 \% ; 38$ of 1186 cells; $n=12)$ in the sham group; the percentages were not significantly different between the CCI and the sham groups (Fig. 5). Thus, the increase in the number of nociceptive-like menthol-sensitive neurons (MS/CS neurons) accounted for the increase in the number of mentholand cold-sensitive neurons after CCI.

We quantified cold- and menthol-evoked membrane currents using the whole-cell patch-clamp recording technique to see whether TRPM8-mediated membrane currents were increased in
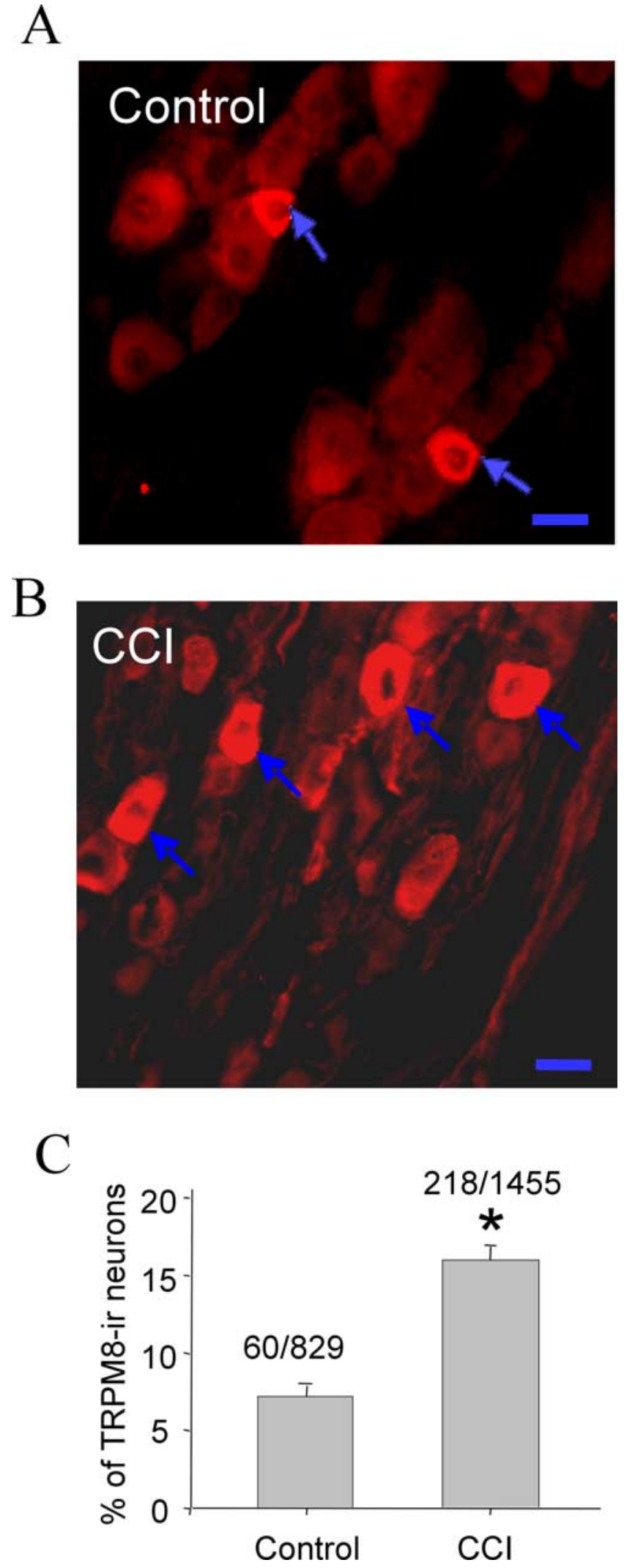

Figure 3. TRPM8 immunostaining in $L 5$ DRGs of the sham and the $\mathrm{CCl}$ rats. $\boldsymbol{A}$, An example shows TRPM8-IR in an L5 DRG section from a sham rat. $\boldsymbol{B}$, An example shows TRPM8-IR in an L5 DRG section from the ipsilateral side of a $\mathrm{CCl}$ rat. Arrows in both $\boldsymbol{A}$ and $\boldsymbol{B}$ indicate TRPM8immunoreactive positive neurons. Scale bars, $20 \mu \mathrm{m}$. $\boldsymbol{C}$, Pooled results show percentage of TRPM8 neurons in L5 DRG sections from the sham rats and the CCl rats. The number of TRPM8immunoreactive positive neurons and the total number of neurons are given on the top of each bar. Error bars indicate mean \pm SEM. ${ }^{*} p<0.05$. 


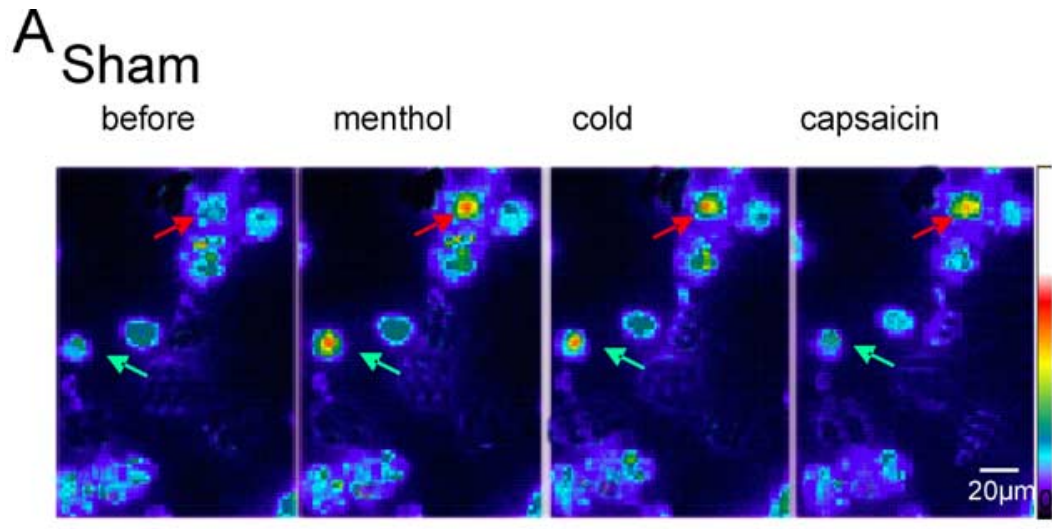

B

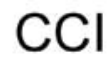

before

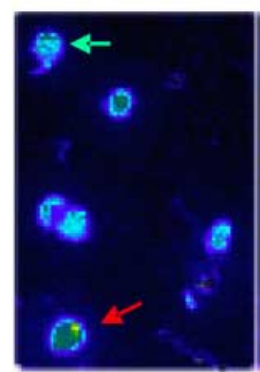

menthol

cold

capsaicin
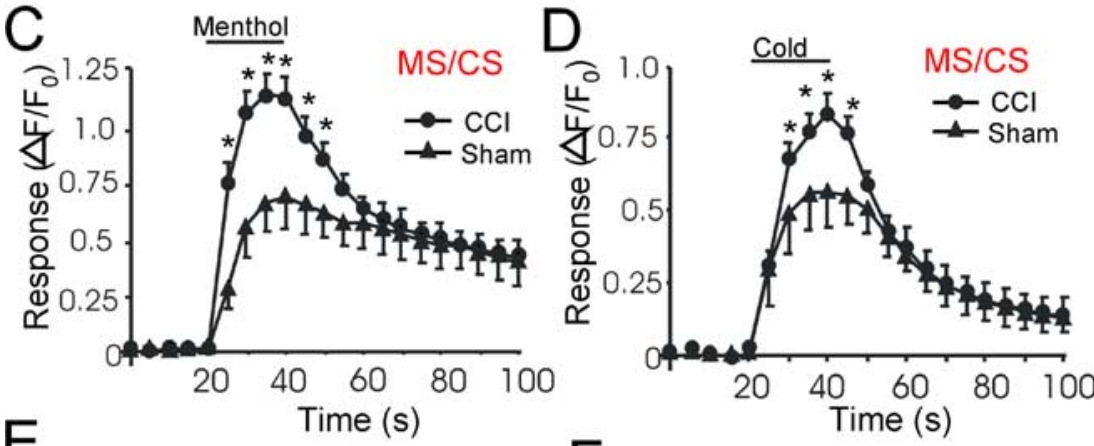

E

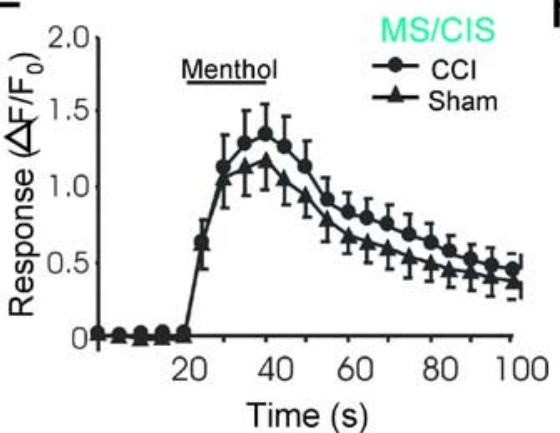

$\mathrm{F}$

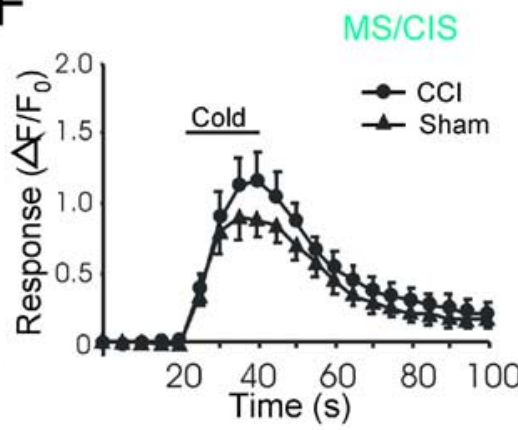

Figure 4. Menthol- and cold-induced responses in capsaicin-sensitive L5 DRG neurons of the sham and the CCl rats. $A$ Images show the fluorescence intensity of the $\mathrm{Ca}^{2+}$ indicator Fluo-3 in DRG neurons of a sham animal before and after the application of menthol $(100 \mu \mathrm{m})$, cold (from $30^{\circ} \mathrm{C}$ to $18^{\circ} \mathrm{C}$ ), and capsaicin $(0.5 \mu \mathrm{m})$. The red arrow indicates a cell that was sensitive to menthol, cold, and capsaicin. The green arrow indicates a cell that was sensitive to menthol and cold but was not sensitive to capsaicin. $\boldsymbol{B}$, Similar to $A$, except the DRG neurons were obtained from a $C(C$ animal. $C$, Pooled results show that menthol responsiveness $\left(\Delta F / F_{0}\right)$ in MS/CS neurons is different between the sham group (filled triangles; $n=18$ ) and the CCl group (filled circles; $n=46$ ). $D$, Similar to $C$, except cold responses were measured in the MS/CS neurons of the sham (filled triangles; $n=18$ ) and the $C\left(\mathrm{Cl}\right.$ (filled circles; $n=46$ ) groups. $E$, Pooled results show menthol responsiveness $\left(\Delta F / F_{0}\right.$ ) in the MS/CIS neurons obtained from either the sham animals (filled triangles; $n=22$ ) or the CCl animals (filled circles; $n=$ 24). $\boldsymbol{F}$, Similar to $\boldsymbol{E}$, except cold responses were measured in the MS/CIS of the sham (filled triangles; $n=22$ ) and the $\mathrm{CCl}$ (filled circles; $n=24$ ) animals. Error bars indicate mean \pm SEM. ${ }^{*} p<0.05$.
L5 DRG neurons of the CCI compared with the sham group. In this set of experiments, L5 DRGs were obtained from the ipsilateral side of the CCI rats or the sham rats. Calcium imaging was first used to identify menthol-sensitive neurons, and patch-clamp recordings were applied to these cells. We found that after the CCI, whole-cell currents evoked by menthol significantly increased in both MS/CS and MS/ CIS neuron populations (Fig. 6). For MS/CS neurons, currents evoked by $100 \mu \mathrm{M}$ menthol had amplitudes of $224 \pm 35 \mathrm{pA}(n=7)$ in the sham group and $822 \pm 218 \mathrm{pA}(n=11)$ in the CCI group (Fig. 6A, $C)(p<0.05)$. The current normalized with cell-surface areas were $0.16 \pm$ $0.05 \mathrm{pA} / \mu \mathrm{m}^{2}(n=7)$ in the sham group and $0.35 \pm 0.06 \mathrm{pA} / \mu \mathrm{m}^{2}(n=11)$ in the CCI group (Fig. $6 D)(p<0.05)$. The currents normalized with cell capacitances were $5.89 \pm 1.53 \mathrm{pA} / \mathrm{pF}$ $(n=6)$ in the sham group and $32.13 \pm 10.03$ $\mathrm{pA} / \mathrm{pF}(n=6)$ in the CCI group $(p<0.05)$. For MS/CIS neurons, currents evoked by 100 $\mu \mathrm{M}$ menthol had amplitudes of $769 \pm 121 \mathrm{pA}$ $(n=11)$ in the sham animals and $1835 \pm 433$ pA $(n=11)$ in the CCI animals (Fig. $6 B, C)$ $(p<0.05)$. The current normalized with cellsurface areas were $0.36 \pm 0.06 \mathrm{pA} / \mu \mathrm{m}^{2}(n=$ $11)$ in the sham group and $1.23 \pm 0.41 \mathrm{pA} / \mu \mathrm{m}^{2}$ $(n=11)$ in the CCI group (Fig. 6D, $p<0.05)$. The currents normalized with cell capacitances were $16.84 \pm 4.44 \mathrm{pA} / \mathrm{pF}(n=6)$ in the sham group and $80.39 \pm 27.9 \mathrm{pA} / \mathrm{pF}(n=6)$ in the CCI group $(p<0.05)$.

Consistent with the enhanced responses to menthol, whole-cell currents evoked by cold stimulation (from $30^{\circ} \mathrm{C}$ to $18^{\circ} \mathrm{C}$ ) also increased in MS/CS neurons (Fig. 7). Currents in MS/CS neurons evoked by the cold stimulation had amplitudes of $70 \pm 17 \mathrm{pA}(n=7)$ in the sham group and $173 \pm 26 \mathrm{pA}(n=11)$ in the CCI group (Fig. $7 A, C)(p<0.05)$. The currents normalized with cell-surface areas were $0.05 \pm$ $0.01 \mathrm{pA} / \mu \mathrm{m}^{2}(n=7)$ in the sham group and $0.11 \pm 0.02 \mathrm{pA} / \mu \mathrm{m}^{2}(n=11)$ in the CCI group (Fig. $7 D)(p<0.05)$. The currents normalized with cell capacitances were $1.45 \pm 0.16 \mathrm{pA} / \mathrm{pF}$ $(n=6)$ in the sham group and $4.07 \pm 1.16$ $\mathrm{pA} / \mathrm{pF}(n=6)$ in the CCI group $(p<0.05)$. For MS/CIS neurons, currents evoked by the cooling temperature had amplitudes of $127 \pm$ $29 \mathrm{pA}(n=11)$ in the sham group and $181 \pm 17$ $\mathrm{pA}(n=11 ; p>0.05)$ in the CCI group (Fig. $7 B, C)$. The currents normalized with cellsurface areas were $0.06 \pm 0.01 \mathrm{pA} / \mu \mathrm{m}^{2}(n=$ 11 ) in the sham group and $0.10 \pm 0.01 \mathrm{pA} / \mu \mathrm{m}^{2}$ $(n=11 ; p>0.05)$ in the CCI group (Fig. $7 D)$. The currents normalized with cell capacitances were $4.27 \pm 1.6 \mathrm{pA} / \mathrm{pF}(n=6)$ in the sham group and $5.72 \pm 0.96 \mathrm{pA} / \mathrm{pF}(n=6)$ in the CCI group $(p>0.05)$.

To establish the relevance between TRPM8mediated responses in in vitro experiments and cold allodynic responses on the skin of hind- 


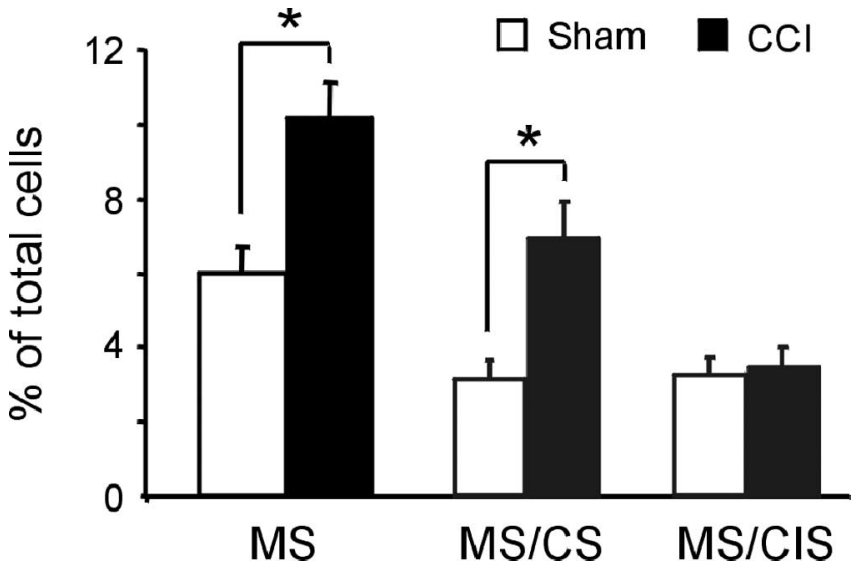

Figure 5. Percentage of menthol-sensitive/cold-sensitive/capsaicin-sensitive neurons in L5 DRGs of the sham and the $\mathrm{CCl}$ rats. The first set of bars shows the percentage of mentholsensitive/cold-sensitive neurons (MS) in ipsilateral L5 DRGs from the sham rats (open bar) and $\mathrm{CCl}$ rats (filled bar). The second set of bars shows the percentage of MS/CS in ipsilateral L5 DRGS from the sham and CCI rats. The third set of bars shows the percentage of MS/CIS in ipsilateral L5 DRGs from the sham and CCI rats. Menthol sensitivity and capsaicin sensitivity were tested with $100 \mu \mathrm{m}$ menthol and $0.5 \mu \mathrm{m}$ capsaicin, respectively. Cold sensitivity was tested by the application of a cold bath solution to cause a temperature drop from $30^{\circ} \mathrm{C}$ to $18^{\circ} \mathrm{C}$ in $20 \mathrm{~s}$. Error bars indicate mean \pm SEM. ${ }^{*} p<0.05$.

limbs in the CCI animals, we asked whether there was an increase in TRPM8-mediated responses in sensory neurons that innervate the cold allodynic skin area. To address this issue, we prelabeled DRG neurons from peripheral targets in vivo by injecting the nerve tracer DiI into the glabrous plantar skin of the hindfoot. The optimum DiI transport time from the glabrous plantar skin of the foot to DRG somas was $\sim 7 \mathrm{~d}$. Before in vitro experiments, rats were examined with the acetone test and were shown to have strong cold allodynic responses. We then removed L4-6 DRGs from the ipsilateral sides of these animals, acutely dissociated neurons, and performed calcium imaging experiments. Figure 8, $A$ and $B$, shows an example of calcium imaging results of a DiIlabeled neuron from a CCI rat responding to the application of menthol $(100 \mu \mathrm{M})$, cold (from $30^{\circ} \mathrm{C}$ to $18^{\circ} \mathrm{C}$ ), and capsaicin $(0.5$ $\mu \mathrm{M})$. DiI-labeled neurons in L4-6 DRGs consisted of a very small fraction in the total DRG population for both the sham and the CCI rats. Of a total of 8190 DRG neurons examined from 18 sham rats (seven dishes, 21 fields), only 171 cells $(2.08 \%)$ were positively labeled with DiI (Fig. 8C); Of the total of 8240 DRG neurons examined from 17 CCI rats (seven dishes, 21 fields), only 166 cells $(2.01 \%)$ were positively labeled with DiI (Fig. $8 C$ ). There was no statistical significance for the distributions of DiI-labeled cells between the CCI and the sham groups ( $\chi^{2}$ test).

When DiI-labeled neurons from the sham animals were tested with menthol $(100 \mu \mathrm{M})$, we found 13 of 171 (7.6\%) labeled neurons responded (Fig. $8 \mathrm{D}$ ). In contrast, when the DiI-labeled neurons from the CCI animals were tested with menthol, 25 of 166 (15\%) DiI-labeled neurons responded to menthol, more than twice of the menthol-sensitive neurons in the sham animals $(p<$ 0.05, $\chi^{2}$ test) (Fig. 8D).

We then classified these menthol-sensitive neurons into MS/CS neurons and MS/CIS neurons by testing with $0.5 \mu \mathrm{M}$ capsaicin. In the 13 menthol-sensitive neurons in the sham group, 4 of them (31\%) were MS/CS neurons, and the remaining 9 cells were MS/CIS neurons (Fig. $8 E$ ). In contrast, in the 25 menthol-sensitive neurons in the CCI group, 19 of them (76\%) were MS/CS neurons, and the remaining 6 cells were MS/CIS neurons, more than twice of the MS/CS neurons in the sham group ( $p<0.05, \chi^{2}$ test) (Fig. $8 E$ ). We tested cold stimulation (from $30^{\circ} \mathrm{C}$ to $18^{\circ} \mathrm{C}$ ) on DiI-labeled menthol-sensitive neurons in the sham $(n=12)$ and the CCI $(n=18)$ groups. We found that all these neurons responded to the cold stimulation. These cells were then classified into capsaicin-sensitive and capsaicin-insensitive groups based on their response to $0.5 \mu \mathrm{M}$ capsaicin. In the sham group, 33\% (4 of 12 cells) of these cells were menthol-sensitive/ cold-sensitive/capsaicin-sensitive neurons. In contrast, in the CCI group, $83 \%$ ( 15 of 18 cells) of these cells were menthol sensitive/cold sensitive/capsaicin sensitive, more than twice of the menthol-sensitive/cold-sensitive/capsaicin-sensitive neurons in the sham group ( $p<0.05, \chi^{2}$ test) (Fig. $\left.8 F\right)$. These results indicated an increase in the population of menthol-sensitive/coldsensitive/capsaicin-sensitive neurons that innervate hindfeet after CCI. When menthol responses of MS/CS neurons in the CCI group were compared with those in the sham groups (Fig. $8 \mathrm{~F}$ ), we found that the peak responses to menthol were significantly higher in the CCI animals $\left(\Delta F / F_{0}=1.2 \pm 0.2 ; n=19\right)$ than in the sham animals $\left(\Delta F / F_{0}=0.81 \pm 0.1 ; n=4 ; p<0.05\right)$. Similarly, the peak responses to cold stimulation (from $30^{\circ} \mathrm{C}$ to $18^{\circ} \mathrm{C}$ ) were also significantly higher in the CCI animals $\left(\Delta F / F_{0}=081 \pm 0.11\right.$; $n=18)$ than in the sham animals $\left(\Delta F / F_{0}=0.35 \pm 0.06 ; n=4\right.$; $p<0.05)$.

\section{Discussion}

We used the CCI model for both in vivo and in vitro studies on TRMP8-mediated responses. The CCI animals reliably showed enhancement of withdrawal reflexes in response to the acetone test, a result similar to previous studies (Bennett and Xie, 1988; Bischofs et al., 2004; Flatters and Bennett, 2004). The cold allodynic responses in the CCI animals well resembles cold allodynia in patients with complex regional pain syndrome (Bennett and Xie, 1988; Kemler et al., 2000; Tahmoush et al., 2000). We used capsazepine, a blocker for both TRPM8 and TRPV1 receptors, for behavioral assessment because no selective TRPM8 antagonist is currently available (Weil et al., 2005). Although capsazepine attenuated cold allodynic responses in the CCI animals, I-RTX, a potent TRPV1 antagonist (Seabrook et al., 2002; Correll et al., 2004; Kanai et al., 2006) that had no inhibitory effect on TRPM8, did not show a similar effect. This suggests that the effect of capsazepine was not attributable to its inhibition to TRPV1. Previous studies have shown that TRPA1 (Bautista et al., 2005), another candidate cold-sensing molecule, is not inhibited by capsazepine (Story et al., 2003). Thus, the effect of capsazepine is most likely mediated by its inhibition to TRPM8; the involvement of TRPM8 in cold allodynia in the CCI rats is suggested. Our pharmacological results are consistent with a recent study in the CCI mice whose TRMP8 receptors are deleted genetically (Colburn et al., 2007).

Mechanisms by which TRPM8 receptor is involved in cold allodynia in our study are revealed by a series of in vitro experiments. In these experiments, the neurons were obtained from ipsilateral L5 DRGs, the target tissues of which include the hindlimb skin. After CCI, there were significant increases in the percentage of TRPM8-immunoreactive positive neurons in the L5 DRGs. These changes suggest an expansion of TRPM8 expression on neurons that normally do not express significant levels of TRPM8. The functional outcomes of such change were demonstrated by $\mathrm{Ca}^{2+}$ imaging experiments showing the significant increases in the percentage of menthol-sensitive/cold-sensitive neurons in the CCI animals. This result suggests a gain of cold sensitivity in the neurons that normally express no sensitivity to cold. The gained cold sensitivity on these neurons was most likely 


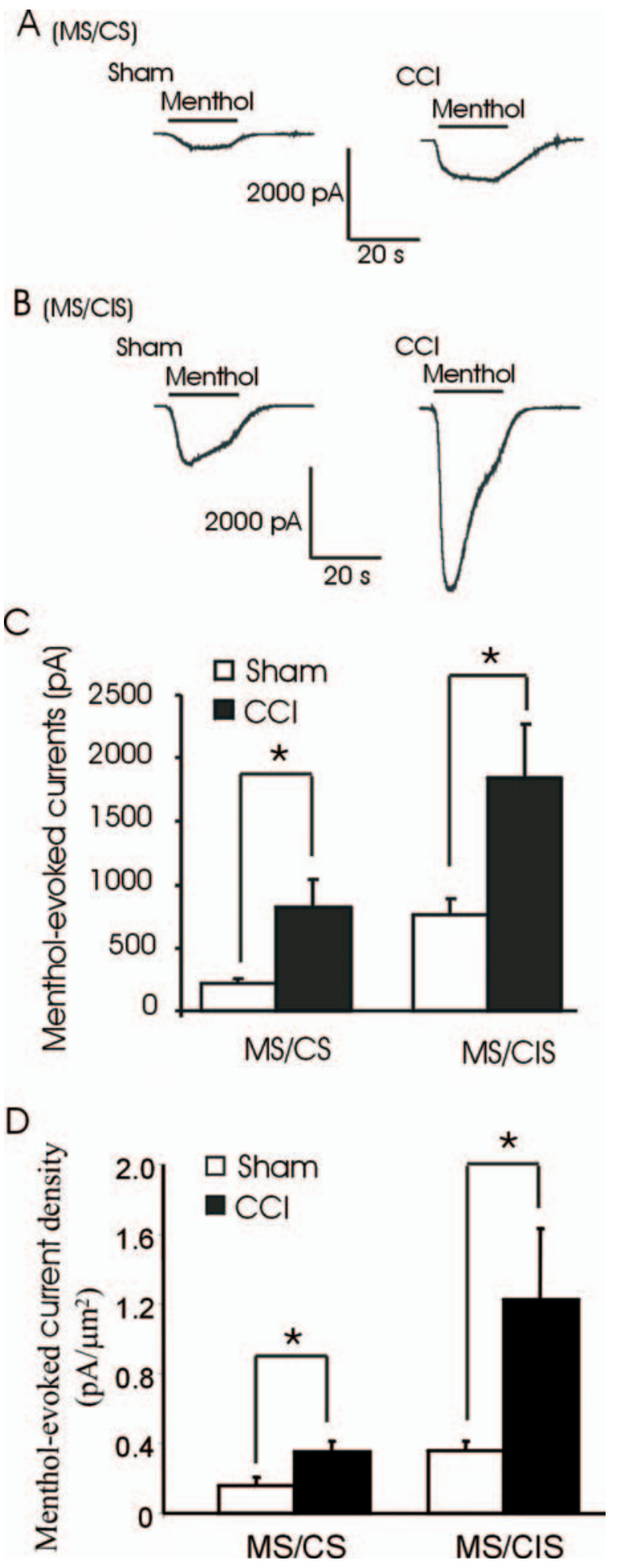

Figure 6. Menthol-evoked whole-cell currents on L5 DRG neurons of the sham and the CCI rats. $A$, Example traces show menthol-evoked whole-cell currents in a MS/CS neuron obtained from a sham rat (left) and menthol-evoked whole-cell currents in a MS/CS neuron obtained from a $\mathrm{CCl}$ rat (right). $\boldsymbol{B}$, Example traces show menthol-evoked whole-cell currents in two MS/CIS neurons, one from a sham rat (left) and the other from a CCl rat (right). $C$, Summary of the experiments illustrated in $\boldsymbol{A}$ and $\boldsymbol{B}$ ( $n=7$ for MS/CS neurons of the sham group; $n=11$ for each of the three remaining groups). $\boldsymbol{D}$, Similar to $\boldsymbol{C}$, except the menthol-evoked currents were normalized by cell-surface areas ( $n=7$ for MS/CS neurons of the sham group; $n=11$ for each of the three remaining groups). Cells were tested with both menthol (100 $\mu \mathrm{m})$ and capsaicin $(0.5 \mu \mathrm{M})$. Experiments were performed at $30^{\circ} \mathrm{C}$. Sensitivity to menthol and capsaicin was tested using $\mathrm{Ca}^{2+}$ imaging before patch-clamp recordings. All CCl rats were pretested to have cold allodynic responses. Error bars indicate mean \pm SEM. ${ }^{*} p<0.05$.
A (MS/CS)

Sham
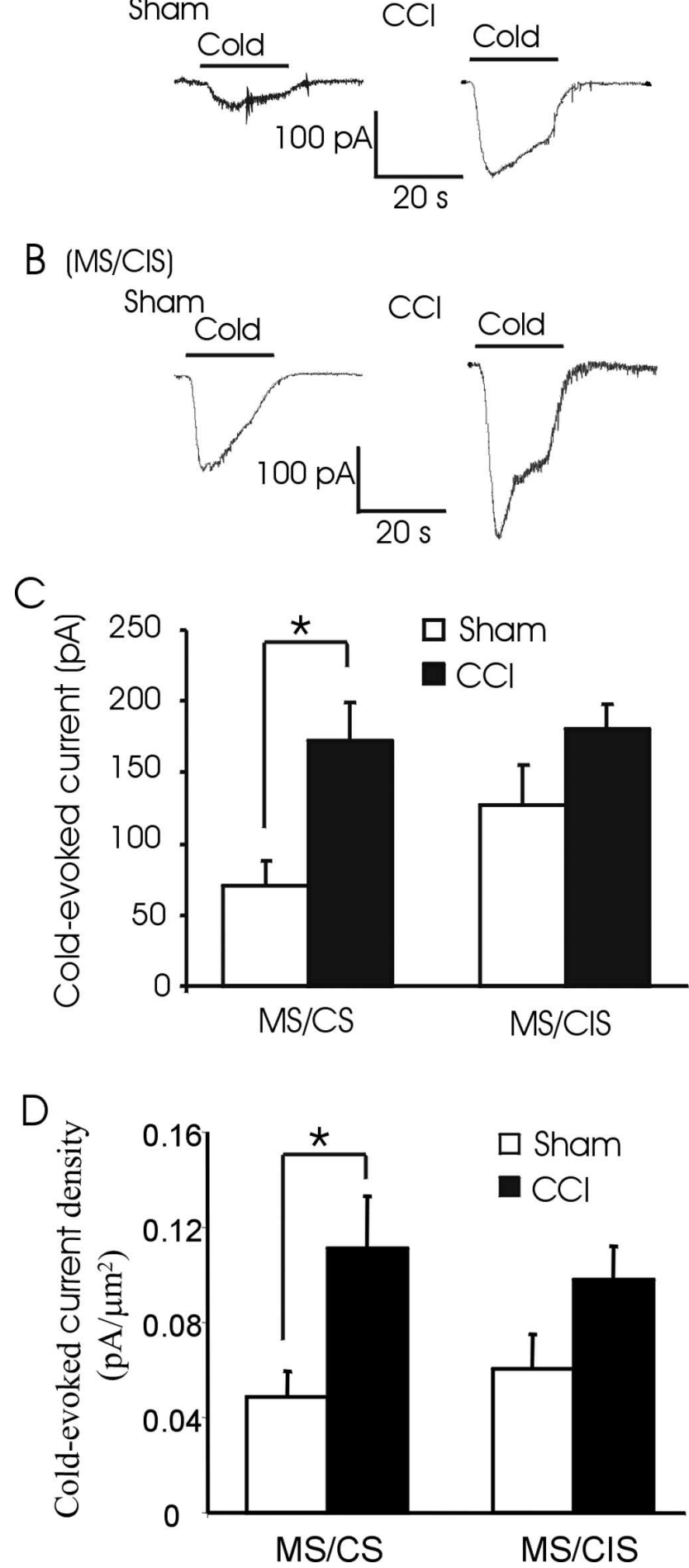

Figure 7. Cold-evoked whole-cell currents on L5 DRG neurons of the sham and the CCI rats $A$, Example traces show cold-evoked whole-cell currents in a MS/CS neuron obtained from a sham control rat (left) and in a MS/CS neuron obtained from a CCI rat (right). $\boldsymbol{B}$, Example traces show cold-evoked whole-cell currents in two MS/CIS neurons, one from a sham rat (left) and the other from a $\mathrm{CCl}$ rat (right). $\boldsymbol{C}$, Summary of the experiments illustrated in $\boldsymbol{A}$ and $\boldsymbol{B}$ ( $n=7$ for $\mathrm{MS} / \mathrm{CS}$ neurons of the sham controls; $n=11$ for each of the remaining groups). $\boldsymbol{D}$, Similar to $\boldsymbol{C}$, except the cold-evoked currents were normalized by cell-surface areas ( $n=7$ for MS/CS neurons of the sham controls; $n=11$ for each of the remaining groups). In all experiments, the basal temperature was $30^{\circ} \mathrm{C}$, and cold stimulation was achieved by a bath solution temperature drop in from $30^{\circ} \mathrm{C}$ to $18^{\circ} \mathrm{C}$ in $20 \mathrm{~s}$. Sensitivity to menthol and capsaicin was tested using $\mathrm{Ca}^{2+}$ imaging before patch-clamp recordings. All $\mathrm{CCl}$ rats were pretested to have cold allodynic responses. Error bars indicate mean \pm SEM. ${ }^{*} p<0.05$. 
mediated by TRPM8 because these neurons also gained the sensitivity to the TRPM8 agonist menthol. More importantly, the percentage of mentholsensitive/cold-sensitive/capsaicin-sensitive neurons was significantly increased in the CCI animals. Previously, we have demonstrated that menthol-sensitive/coldsensitive/capsaicin-sensitive neurons featured nociceptive neuron properties (Xing et al., 2006). Thus, the gain of TRPM8-mediated cold sensitivity occurred in nociceptivelike neurons after CCI. The increases in the percentage of menthol-sensitive/cold-sensitive/capsaicin-sensitive neurons represented the increased number of these cells. This conclusion is supported by the experiment performed on retrograde-labeled cells because the total numbers of the labeled neurons were similar between the CCI group and the sham group.

We found that, with both $\mathrm{Ca}^{2+}$ imaging and patch-clamp experiments, there is increased responsiveness to both menthol and cold in menthol-sensitive neurons of the CCI group compared with the sham group. The enhanced currents evoked by cold in the CCI group suggest that these neurons are more excitable to cold stimuli. More relevant to the innocuous coldinduced nociception was that the coldand menthol-evoked currents were significantly enhanced in capsaicin-sensitive neurons. Likewise, our results on retrograde-labeled neurons indicate that TRPM8-mediated responses were enhanced in the capsaicin-sensitive neurons that innervated the skin of the ipsilateral hindlimbs in the CCI group. These results are consistent with the cold allodynic behavioral responses observed on the ipsilateral hindlimbs of the CCI group. Thus, the MS/CS afferent fibers are most likely to be a nociceptive pathway that accounts for cold allodynia in the CCI animals.

We have shown that almost all neurons sensitive to menthol are also sensitive to cold stimulation. However, others have observed that some menthol-sensitive cells did not respond to cold (Nealen et al., 2003; Mahieu et al., 2006; Dhaka et al., 2007) and that the menthol responses in these cells were attributable to TRPM8independent $\mathrm{Ca}^{2+}$ release. Factors that might contribute to the discrepancy include the concentrations of menthol, the degree of cooling temperatures, the threshold setting for detecting $\mathrm{Ca}^{2+}$ responses, and the cell types. Recently, a study showed that menthol could activate mouse TRPA1 receptors (Karashima et al., 2007). This raises a possibility that a small portion of menthol-sensitive neurons in

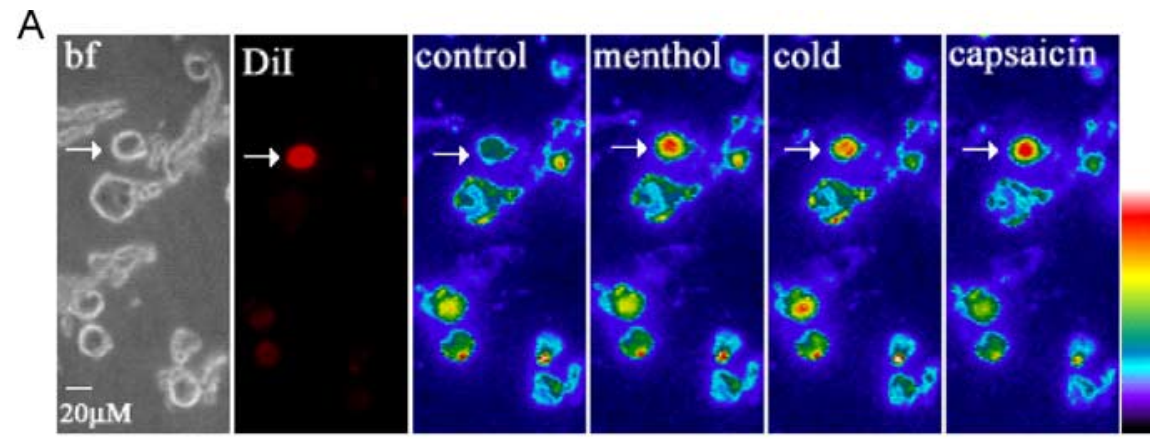

B
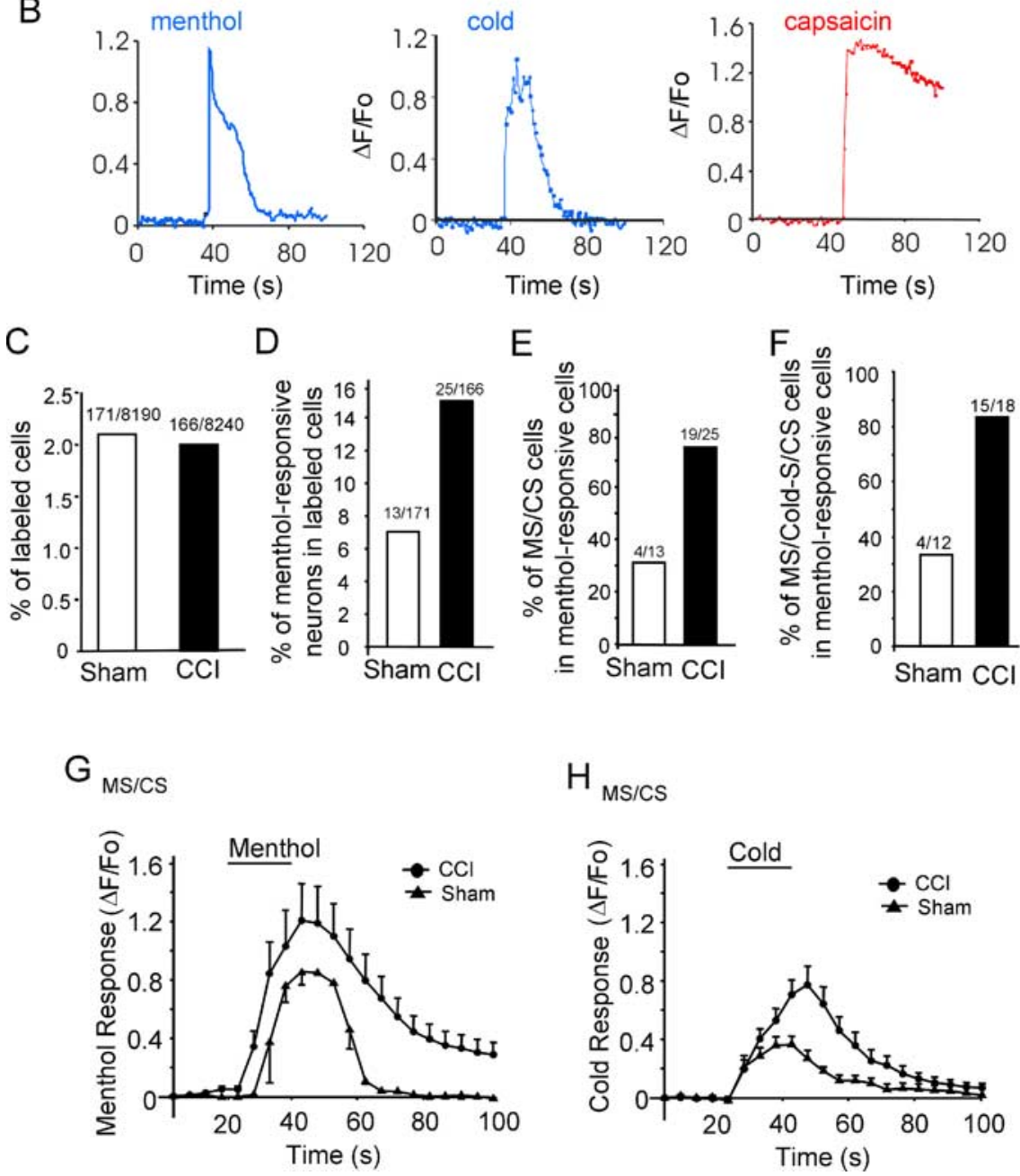

Figure 8. Menthol- and cold-evoked responses in Dil retrograde-labeled DRG neurons that innervate the skin of hindlimbs. $\boldsymbol{A}$, Example images show a Dil-labeled neuron (arrow) viewed under bright light (bf; first panel), UV light for Dil (second panel), and fluorescence light for $\mathrm{Ca}^{2+}$ imaging (third to sixth panels). After taking images under control condition (third panel), the neuron was tested with menthol (100 $\mu \mathrm{m}$; fourth panel), cold stimulation (from $30^{\circ} \mathrm{C}$ to $18^{\circ} \mathrm{C}$; fifth panel), and capsaicin $(0.5 \mu \mathrm{m}$; sixth panel). Neurons were acutely dissociated from ipsilateral L4 -6 DRGs of a CCI rat given an injection of Dil to the hindpaw. $B$, Traces show the responses $\left(\Delta F / F_{0}\right)$ of the Dil-labeled neuron in $\boldsymbol{A}$ to menthol (left), cold (middle), and capsaicin (right). C, Percentage of Dil-labeled neurons obtained from the sham rats (18 rats) and the $C(\mathrm{Cl}$ rats (17 rats). The number of Dil-labeled neurons and the total number of neurons are indicated on the top of each bar. $\boldsymbol{D}$, The Dil-labeled neurons shown in C were tested with menthol ( 100 $\mu \mathrm{m})$. The bar graph shows the percentage of menthol-sensitive neurons in the Dil-labeled cells in the sham and the $\mathrm{CCl}$ groups. The cell numbers are indicated on the top of each bar. $\boldsymbol{E}$, Percentage of MS/CS neurons in Dil-labeled menthol-sensitive cells. The cell numbers are indicated on the top of each bar. $\boldsymbol{F}$, Percentage of menthol-sensitive/cold-sensitive/capsaicin-sensitive (MS/Cold-S/ (S) neurons in Dil-labeled menthol-sensitive neurons. The cell numbers are indicated on the top of each bar. $\mathbf{G}$, Menthol responses of Dil-labeled MS/CS neurons in the CCl group ( $n=19$; filled circles) and the sham group ( $n=4$; triangles) and cold responses of Dil-labeled MS/CS cells in the CCI group ( $n=15$; filled circles) and the sham group ( $n=4$; filled triangles). All the CCl rats included in these experiments had cold allodynia. Error bars indicate mean \pm SEM. ${ }^{*} p<0.05$. 
rats may be TRPA1-expressing neurons. However, neurons that respond to both menthol and innocuous cold are thought to be mostly TRPM8-expressing neurons (Dhaka et al., 2007). It is currently unclear whether TRPA1 is a cold temperature sensor in primary afferent neurons, an issue that remains to be very controversial and hotly debated in the field (Story et al., 2003; Babes et al., 2004; Jordt et al., 2004; Nagata et al., 2005; Katsura et al., 2006; Kwan et al., 2006; Zurborg et al., 2007).

The increases in the population of TRPM8-immunoreactive positive cells and menthol-sensitive neurons in the CCI group suggest an upregulation of TRPM8 expression after chronic nerve injury. In a recent anatomic study, however, no significant change in TRPM8 expression was observed in the spinal nerve transection model (Obata et al., 2005). The discrepancy could be attributable to the differences in the nerve injury models. A discrepancy between the two different nerve injury models has been observed for the changes of the expression of other sensory molecules such as P2X3 receptors (Bradbury et al., 1998; Tsuzuki et al., 2001). In addition, different animal models have been found to yield different degrees of cold allodynic responses. The CCI animal model is shown to have the most pronounced cold allodynic responses (Allchorne et al., 2005). Therefore, the upregulation of TRPM8 shown in our study is not inconsistent with the study performed on the nerve transaction animal model. In fact, upregulation of TRPM8 has been previously demonstrated in cultured DRG neurons in a NGF-dependent manner (Babes et al., 2004), and NGF levels are known to become elevated under neuropathic conditions including chronic nerve injury (Heumann et al., 1987; Funakoshi et al., 1993; Herzberg et al., 1997). Moreover, a recent anatomical study has shown increased TRPM8-IR in DRGs of the CCI animals (Proudfoot et al., 2006). Although our study suggests that upregulation of TRPM8 expression is a mechanism of cold allodynia, it would be interesting to study signaling pathways for TRPM8 upregulation under pathological conditions.

The enhancement of menthol/cold-evoked currents in the CCI group could also be attributable to the post-transcription modulation of TRPM8. For other sensory receptors such as TRPV1, post-transcriptional modulation occurs after the stimulation of TRPV1-expressing neurons by mediators including bradykinin, prostaglandin $\mathrm{E}_{2}\left(\mathrm{PGE}_{2}\right), \mathrm{ATP}$, and NGF (Jordt et al., 2003). These sensitize TRPV1 receptors to heat. However, unlike TRPV1, a number of studies have failed to show TRPM8 sensitization when cells were stimulated by mediators such as $\mathrm{PGE}_{2}$, bradykinin, and 5-HT. In contrast, these mediators only desensitized TRPM8 (Abe et al., 2005; Premkumar et al., 2005; Linte et al., 2007). Intracellular messenger systems including phosphatidylinositol-4,5-bisphosphate and protein kinases have be shown to be involved in TRPM8 desensitization (Liu and Qin, 2005; Premkumar et al., 2005). These observations favor the idea that upregulation of TRPM8 expression contributes to the enhancement of menthol- and cold-evoked currents in the CCI group. Nevertheless, a more resent study has shown that TRPM8 can be sensitized by lysophosphatidylcholine, the membrane lipid released after phospholipase $\mathrm{A}_{2}$ activation (Andersson et al., 2007), raising a possibility that TRPM8 post-transcriptional modulation may also account for the enhanced menthol/coldevoked currents in the CCI group.

In addition to TRPM8, other mechanisms have been suggested to contribute to the sensitivity of a sensory neuron to cold temperatures, including inhibition of $\mathrm{Na}^{+} / \mathrm{K}^{+}$-ATPases, decrease in "background" $\mathrm{K}^{+}$conductances (Viana et al., 2002), and activation of TRPA1 (Story et al., 2003). Consistently, we and others observed that some menthol-insensitive neurons responded to cold (Nealen et al., 2003; Babes et al., 2006; Dhaka et al., 2007; Munns et al., 2007). TRPA1 was shown to be a noxious cold receptor in mice (Story et al., 2003), but the involvement of TRPA1 in sensing cold has been questioned in the rat sensory system (Babes et al., 2004; Jordt et al., 2004; McKemy, 2005; Nagata et al., 2005). Upregulation of the TRPA1 was suggested to be associated with hyperalgesia to noxious cold in a nerve transaction rat model (Obata et al., 2005), but the study did not examine innocuous cold stimulation. Future studies on TRPA1 and other cold-sensing candidates may give more insights into the mechanism(s) of cold allodynia under pathological conditions. Our findings suggest the involvement of TRPM8 in cold allodynia and therapeutic uses of TRPM8 antagonists. Interestingly, a recent study has reported that TRPM8 agonists can suppress mechanical and heat nociception in the CCI animals through a central modulation (Proudfoot et al., 2006) and TRPM8mediated analgesic effects are supported by the study using TRPM8 knock-out mice (Dhaka et al., 2007). Thus, depending on pain conditions, both TRPM8 receptor antagonists and agonists may be useful clinically for pain management.

\section{References}

Abe J, Hosokawa H, Okazawa M, Kandachi M, Sawada Y, Yamanaka K, Matsumura K, Kobayashi S (2005) TRPM8 protein localization in trigeminal ganglion and taste papillae. Brain Res Mol Brain Res 136:91-98.

Abe J, Hosokawa H, Sawada Y, Matsumura K, Kobayashi S (2006) Ca(2+)dependent PKC activation mediates menthol-induced desensitization of transient receptor potential M8. Neurosci Lett 397:140-144.

Allchorne AJ, Broom DC, Woolf CJ (2005) Detection of cold pain, cold allodynia and cold hyperalgesia in freely behaving rats. Mol Pain 1:36.

Andersson DA, Nash M, Bevan S (2007) Modulation of the cold-activated channel TRPM8 by lysophospholipids and polyunsaturated fatty acids. J Neurosci 27:3347-3355.

Babes A, Zorzon D, Reid G (2004) Two populations of cold-sensitive neurons in rat dorsal root ganglia and their modulation by nerve growth factor. Eur J Neurosci 20:2276-2282.

Babes A, Zorzon D, Reid G (2006) A novel type of cold-sensitive neuron in rat dorsal root ganglia with rapid adaptation to cooling stimuli. Eur J Neurosci 24:691-698.

Bautista DM, Movahed P, Hinman A, Axelsson HE, Sterner O, Hogestatt ED, Julius D, Jordt SE, Zygmunt PM (2005) Pungent products from garlic activate the sensory ion channel TRPA1. Proc Natl Acad Sci USA 102:12248-12252.

Bautista DM, Siemens J, Glazer JM, Tsuruda PR, Basbaum AI, Stucky CL, Jordt SE, Julius D (2007) The menthol receptor TRPM8 is the principal detector of environmental cold. Nature 448:204-208.

Behrendt HJ, Germann T, Gillen C, Hatt H, Jostock R (2004) Characterization of the mouse cold-menthol receptor TRPM8 and vanilloid receptor type-1 VR1 using a fluorometric imaging plate reader (FLIPR) assay. Br J Pharmacol 141:737-745.

Bennett GJ, Xie YK (1988) A peripheral mononeuropathy in rat that produces disorders of pain sensation like those seen in man. Pain 33:87-107.

Bischofs S, Zelenka M, Sommer C (2004) Evaluation of topiramate as an anti-hyperalgesic and neuroprotective agent in the peripheral nervous system. J Peripher Nerv Syst 9:70-78.

Bradbury EJ, Burnstock G, McMahon SB (1998) The expression of P2X3 purinoreceptors in sensory neurons: effects of axotomy and glial-derived neurotrophic factor. Mol Cell Neurosci 12:256-268.

Choi Y, Yoon YW, Na HS, Kim SH, Chung JM (1994) Behavioral signs of ongoing pain and cold allodynia in a rat model of neuropathic pain. Pain 59:369-376.

Chung MK, Caterina MJ (2007) TRP channel knockout mice lose their cool. Neuron 54:345-347.

Colburn RW, Lubin ML, Stone Jr DJ, Wang Y, Lawrence D, D’Andrea MR, Brandt MR, Liu Y, Flores CM, Qin N (2007) Attenuated cold sensitivity in TRPM8 null mice. Neuron 54:379-386.

Correll CC, Phelps PT, Anthes JC, Umland S, Greenfeder S (2004) Cloning 
and pharmacological characterization of mouse TRPV1. Neurosci Lett 370:55-60.

Dhaka A, Murray AN, Mathur J, Earley TJ, Petrus MJ, Patapoutian A (2007) TRPM8 is required for cold sensation in mice. Neuron 54:371-378.

Flatters SJ, Bennett GJ (2004) Ethosuximide reverses paclitaxel- and vincristine-induced painful peripheral neuropathy. Pain 109:150-161.

Funakoshi H, Frisen J, Barbany G, Timmusk T, Zachrisson O, Verge VM, Persson H (1993) Differential expression of mRNAs for neurotrophins and their receptors after axotomy of the sciatic nerve. J Cell Biol 123:455-465.

Herzberg U, Eliav E, Dorsey JM, Gracely RH, Kopin IJ (1997) NGF involvement in pain induced by chronic constriction injury of the rat sciatic nerve. NeuroReport 8:1613-1618.

Heumann R, Lindholm D, Bandtlow C, Meyer M, Radeke MJ, Misko TP, Shooter E, Thoenen H (1987) Differential regulation of mRNA encoding nerve growth factor and its receptor in rat sciatic nerve during development, degeneration, and regeneration: role of macrophages. Proc Natl Acad Sci USA 84:8735-8739.

Jordt SE, McKemy DD, Julius D (2003) Lessons from peppers and peppermint: the molecular logic of thermosensation. Curr Opin Neurobiol 13:487-492.

Jordt SE, Bautista DM, Chuang HH, McKemy DD, Zygmunt PM, Hogestatt ED, Meng ID, Julius D (2004) Mustard oils and cannabinoids excite sensory nerve fibres through the TRP channel ANKTM1. Nature 427:260-265.

Kanai Y, Hara T, Imai A (2006) Participation of the spinal TRPV1 receptors in formalin-evoked pain transduction: a study using a selective TRPV1 antagonist, iodo-resiniferatoxin. J Pharm Pharmacol 58:489-493.

Karashima Y, Damann N, Prenen J, Talavera K, Segal A, Voets T, Nilius B (2007) Bimodal action of menthol on the transient receptor potential channel TRPA1. J Neurosci 27:9874-9884.

Katsura H, Obata K, Mizushima T, Yamanaka H, Kobayashi K, Dai Y, Fukuoka T, Tokunaga A, Sakagami M, Noguchi K (2006) Antisense knock down of TRPA1, but not TRPM8, alleviates cold hyperalgesia after spinal nerve ligation in rats. Exp Neurol 200:112-123.

Kemler MA, Schouten HJ, Gracely RH (2000) Diagnosing sensory abnormalities with either normal values or values from contralateral skin: comparison of two approaches in complex regional pain syndrome I. Anesthesiology 93:718-727.

Kwan KY, Allchorne AJ, Vollrath MA, Christensen AP, Zhang DS, Woolf CJ, Corey DP (2006) TRPA1 contributes to cold, mechanical, and chemical nociception but is not essential for hair-cell transduction. Neuron 50:277-289.

Levine JD, Alessandri-Haber N (2007) TRP channels: targets for the relief of pain. Biochim Biophys Acta 1772:989-1003.

Linte RM, Ciobanu C, Reid G, Babes A (2007) Desensitization of cold- and menthol-sensitive rat dorsal root ganglion neurones by inflammatory mediators. Exp Brain Res 178:89-98.

Liu B, Qin F (2005) Functional control of cold- and menthol-sensitive TRPM8 ion channels by phosphatidylinositol 4,5-bisphosphate. J Neurosci 25:1674-1681.

Mahieu F, Owsianik G, Verbert L, Janssens A, De Smedt H, Nilius B, Voets T (2006) TRPM8-independent MENTHOL-induced Ca2+ release from endoplasmic reticulum and golgi, J Biol Chem 282:3325-3336.

McKemy DD (2005) How cold is it? TRPM8 and TRPA1 in the molecular logic of cold sensation. Mol Pain 1:16.

McKemy DD, Neuhausser WM, Julius D (2002) Identification of a cold receptor reveals a general role for TRP channels in thermosensation. Nature 416:52-58.

Munns C, AlQatari M, Koltzenburg M (2007) Many cold sensitive peripheral neurons of the mouse do not express TRPM8 or TRPA1. Cell Calcium 41:331-342.

Nagata K, Duggan A, Kumar G, Garcia-Anoveros J (2005) Nociceptor and hair cell transducer properties of TRPAl, a channel for pain and hearing. J Neurosci 25:4052-4061.

Nealen ML, Gold MS, Thut PD, Caterina MJ (2003) TRPM8 mRNA is expressed in a subset of cold-responsive trigeminal neurons from rat. J Neurophysiol 90:515-520.

Obata K, Katsura H, Mizushima T, Yamanaka H, Kobayashi K, Dai Y,
Fukuoka T, Tokunaga A, Tominaga M, Noguchi K (2005) TRPA1 induced in sensory neurons contributes to cold hyperalgesia after inflammation and nerve injury. J Clin Invest 115:2393-2401.

Okazawa M, Terauchi T, Shiraki T, Matsumura K, Kobayashi S (2000) l-Menthol-induced $[\mathrm{Ca} 2+] \mathrm{i}$ increase and impulses in cultured sensory neurons. NeuroReport 11:2151-2155.

Okazawa M, Inoue W, Hori A, Hosokawa H, Matsumura K, Kobayashi S (2004) Noxious heat receptors present in cold-sensory cells in rats. Neurosci Lett 359:33-36.

Peier AM, Moqrich A, Hergarden AC, Reeve AJ, Andersson DA, Story GM, Earley TJ, Dragoni I, McIntyre P, Bevan S, Patapoutian A (2002) A TRP channel that senses cold stimuli and menthol. Cell 108:705-715.

Petruska JC, Cooper BY, Gu JG, Rau KK, Johnson RD (2000a) Distribution of $\mathrm{P} 2 \mathrm{X} 1, \mathrm{P} 2 \mathrm{X} 2$, and $\mathrm{P} 2 \mathrm{X} 3$ receptor subunits in rat primary afferents: relation to population markers and specific cell types. J Chem Neuroanat 20:141-162.

Petruska JC, Napaporn J, Johnson RD, Gu JG, Cooper BY (2000b) Subclassified acutely dissociated cells of rat DRG: histochemistry and patterns of capsaicin-, proton-, and ATP-activated currents. J Neurophysiol 84:2365-2379.

Petruska JC, Napaporn J, Johnson RD, Cooper BY (2002) Chemical responsiveness and histochemical phenotype of electrophysiologically classified cells of the adult rat dorsal root ganglion. Neuroscience 115:15-30.

Premkumar LS, Raisinghani M, Pingle SC, Long C, Pimentel F (2005) Downregulation of transient receptor potential melastatin 8 by protein kinase C-mediated dephosphorylation. J Neurosci 25:11322-11329.

Proudfoot CJ, Garry EM, Cottrell DF, Rosie R, Anderson H, Robertson DC, Fleetwood-Walker SM, Mitchell R (2006) Analgesia mediated by the TRPM8 cold receptor in chronic neuropathic pain. Curr Biol 16:1591-1605.

Reid G, Flonta ML (2002) Ion channels activated by cold and menthol in cultured rat dorsal root ganglion neurones. Neurosci Lett 324:164-168.

Seabrook GR, Sutton KG, Jarolimek W, Hollingworth GJ, Teague S, Webb J, Clark N, Boyce S, Kerby J, Ali Z, Chou M, Middleton R, Kaczorowski G, Jones $\mathrm{AB}$ (2002) Functional properties of the high-affinity TRPV1 (VR1) vanilloid receptor antagonist (4-hydroxy-5-iodo-3methoxyphenylacetate ester) iodo-resiniferatoxin. J Pharmacol Exp Ther 303:1052-1060.

Story GM, Peier AM, Reeve AJ, Eid SR, Mosbacher J, Hricik TR, Earley TJ, Hergarden AC, Andersson DA, Hwang SW, McIntyre P, Jegla T, Bevan S, Patapoutian A (2003) ANKTM1, a TRP-like channel expressed in nociceptive neurons, is activated by cold temperatures. Cell 112:819-829.

Tahmoush AJ, Schwartzman RJ, Hopp JL, Grothusen JR (2000) Quantitative sensory studies in complex regional pain syndrome type 1/RSD. Clin J Pain 16:340-344.

Thut PD, Wrigley D, Gold MS (2003) Cold transduction in rat trigeminal ganglia neurons in vitro. Neuroscience 119:1071-1083.

Tominaga M, Caterina MJ (2004) Thermosensation and pain. J Neurobiol 61:3-12.

Tsuzuki K, Kondo E, Fukuoka T, Yi D, Tsujino H, Sakagami M, Noguchi K (2001) Differential regulation of P2X(3) mRNA expression by peripheral nerve injury in intact and injured neurons in the rat sensory ganglia. Pain 91:351-360.

Viana F, de la Pena E, Belmonte C (2002) Specificity of cold thermotransduction is determined by differential ionic channel expression. Nat Neurosci 5:254-260.

Vierck Jr CJ, Acosta-Rua AJ, Johnson RD (2005) Bilateral chronic constriction of the sciatic nerve: a model of long-term cold hyperalgesia. J Pain 6:507-517.

Vinik AI (2004) Advances in diabetes for the millennium: new treatments for diabetic neuropathies. Med Gen Med 6:13.

Weil A, Moore SE, Waite NJ, Randall A, Gunthorpe MJ (2005) Conservation of functional and pharmacological properties in the distantly related temperature sensors TRVP1 and TRPM8. Mol Pharmacol 68:518-527.

Xing H, Ling J, Chen M, Gu JG (2006) Chemical and cold sensitivity of two distinct populations of TRPM8-expressing somatosensory neurons. J Neurophysiol 95:1221-1230.

Zurborg S, Yurgionas B, Jira JA, Caspani O, Heppenstall PA (2007) Direct activation of the ion channel TRPA1 by $\mathrm{Ca}^{2+}$. Nat Neurosci 10:277-279. 